\title{
Review Article \\ Obstructive Sleep Apnea, Oxidative Stress and Cardiovascular Disease: Lessons from Animal Studies
}

\author{
Rio Dumitrascu, Joerg Heitmann, Werner Seeger, Norbert Weissmann, and Richard Schulz
}

Department of Sleep Medicine, University of Giessen Lung Center, Klinikstrasse 33, 35392 Giessen, Germany

Correspondence should be addressed to Richard Schulz; richard.schulz@innere.med.uni-giessen.de

Received 9 December 2012; Accepted 22 January 2013

Academic Editor: Sumitra Miriyala

Copyright (C) 2013 Rio Dumitrascu et al. This is an open access article distributed under the Creative Commons Attribution License, which permits unrestricted use, distribution, and reproduction in any medium, provided the original work is properly cited.

Obstructive sleep apnea (OSA) is an independent risk factor for cardiovascular (CV) diseases such as arterial hypertension, heart failure, and stroke. Based on human research, sympathetic activation, inflammation, and oxidative stress are thought to play major roles in the pathophysiology of OSA-related CV diseases. Animal models of OSA have shown that endothelial dysfunction, vascular remodelling, and systemic and pulmonary arterial hypertension as well as heart failure can develop in response to chronic intermittent hypoxia $(\mathrm{CIH})$. The available animal data are clearly in favour of oxidative stress playing a key role in the development of all of these CV manifestations of OSA. Presumably, the oxidative stress is due to an activation of NADPH oxidase and other free oxygen radicals producing enzymes within the CV system as evidenced by data from knockout mice and pharmacological interventions. It is hoped that animal models of OSA-related CV disease will continue to contribute to a deeper understanding of their underlying pathophysiology and will foster the way for the development of cardioprotective treatment options other than conventional CPAP therapy.

\section{Introduction}

Obstructive sleep apnea (OSA) is a highly prevalent sleeprelated breathing disorder presenting with the clinical hallmarks of snoring, witnessed nocturnal apneas, and excessive daytime sleepiness. It is caused by repetitive collapse of a narrow upper airway during sleep with the main predisposing factor being obesity [1]. Large-scale epidemiological studies have clearly shown that untreated OSA is an independent cardiovascular (CV) risk factor. Amongst others, severe OSA (i.e., with an apnea-hypopnea-index (AHI) exceeding 30 per hour of sleep) can contribute to the emergence of arterial hypertension, heart failure, stroke, and pulmonary hypertension [2-4]. In addition, otherwise healthy OSA patients can already display more subtle $\mathrm{CV}$ changes such as endothelial dysfunction and vascular remodelling $[5,6]$.

Based on data obtained in patients with OSA, it is currently believed that sympathetic activation, inflammation, and oxidative stress play major roles in the pathophysiology of OSA-related CV diseases [7-10]. However, due to various reasons, the possibilities to conduct further human research into the relationship between OSA and CV diseases are limited. First, OSA patients often present with confounding factors increasing per se CV risk such as obesity, concomitant metabolic disease, and smoking. Second, CV diseases in OSA patients often need many years to develop in order to be diagnosed clinically. Third, it is difficult to perform more invasive experimental procedures in these patients.

These drawbacks may be overcome by using animal models of OSA. In most animal studies, only the cyclical pattern of hypoxia characteristic of OSA is simulated [11] (Figure 1). For this purpose, animals are housed in a chamber and cyclically exposed either to normoxia/hypoxia or room air in a computer controlled manner.

Depending on animal species, type of stimuli, and technical approaches, there are many animal models described in the literature. The duration (from 30 seconds up to $30 \mathrm{~min}$ ) of hypoxic exposure generally varies indirectly to the frequency of events (2 to 120/hour) [12-21], and this issue may contribute to discrepancies in the literature. However, the standard animal model is represented by chronic intermittent exposure of rodents to an $\mathrm{FiO} 2$ nadir of $6-10 \%$ for $30 \mathrm{sec}$ to 1 min which results in oxyhemoglobin desaturation of about $60 \%$ to $80 \%$ (Figure 1 ). 


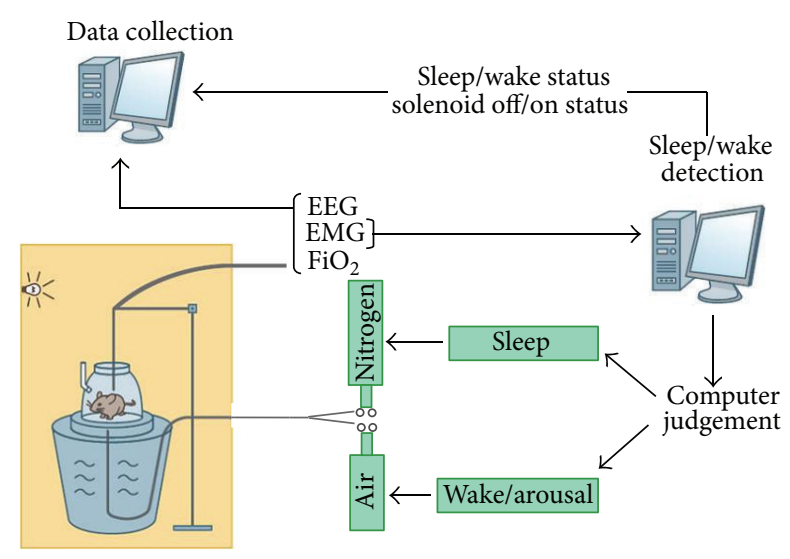

FIGURE 1: Schematic representation of the mouse/rat model simulating OSA-associated CIH. Animals are housed in plexiglass chambers and are repetitively exposed either to room air (i.e., $21 \% \mathrm{O}_{2}$ ) or nitrogen (i.e., hypoxia). Exposure to $\mathrm{CIH}$ may be synchronized to the sleep-wake cycle by simultaneously measuring EEG and EMG activities of animals.

It should be recognized that the above-mentioned experimental conditions primarily mimic severe forms of human sleep apnea with AHI $>30 / h$. Furthermore, some of the human OSA characteristics are not highlighted in this experimental model. For example, the model fails to reproduce upper airway occlusion, intrathoracic pressure swings, arousals, and hypercapnia. On the other hand, reproducing a single characteristic of clinical OSA by exposure to cyclical hypoxia appears to be relevant in order to induce pathophysiological changes similar to clinical manifestations of patients suffering from OSA. Thus, animals exposed to $\mathrm{CIH}$ develop after 3 to 5 weeks pathological changes similar to those found in OSA patients such as endothelial dysfunction, atherosclerosis, arterial hypertension, pulmonary hypertension, and heart failure. Regardless of these considerations, other more complex models have also been developed which additionally reflect the nonhypoxic stimuli linked to OSA and may thus give a more realistic picture of the human disease $[22,23]$.

In the present paper, we will discuss the animal models of OSA and their respective contributions to a deeper understanding of the CV consequences of OSA. Within this frame, we will focus on oxidative stress as the most relevant intermediary pathogenetic mechanism. The $\mathrm{CIH}$ exposure induces tissue deoxygenation followed rapidly by tissue reoxygenation leading to ROS formation.

A few ROS-generating systems are described in the literature including NADPH oxidase (NOX), xanthine oxidase, mitochondrial chain, and uncoupled nitric oxide synthase (NOS). Probably, NOX is the most important enzyme in the setting of $\mathrm{CIH}$ as will be discussed in the following sections. The deleterious effects of ROS on the CV system are primarily exerted by unspecific oxidation of biological compounds (DNA, protein, lipid, etc.) and modulation of specific signalling pathways (i.e., redox signalling). In addition, ROS may activate the sympathetic nervous system and enhance inflammatory processes thus acting as master regulators in the pathogenesis of OSA-associated CV diseases.

\section{Endothelial Dysfunction}

Otherwise healthy, nonsmoking OSA patients have been shown to suffer from endothelial dysfunction, that is, a reduction of endothelial-dependent vasodilation, which may be relieved by effective continuous positive airway pressure (CPAP) therapy $[6,24]$. Animal studies clearly suggest that the endothelial dysfunction characteristic of OSA is the result of an increased oxidative stress with reduced bioavailability of nitric oxide (NO).

Rats exposed to chronic intermittent hypoxia $(\mathrm{CIH})$ exhibit a reduced vasodilation in response to infusions of the NO liberator acetylcholine and reduced vasoconstriction following NO synthase inhibition [25]. Furthermore, treatment of $\mathrm{CIH}$-exposed rats with the superoxide dismutase (SOD) mimetic tempol restores vascular reactivity [26]. Investigations of in vitro vasoreactivity of isolated coronary and cerebral arteries from mice have found that an activation of NOX is probably responsible for the occurrence of endothelial dysfunction in response to $\mathrm{CIH}$ [27].

Similar findings were reported by Liu et al. [28] describing erectile dysfunction in $\mathrm{CIH}$ rats due to increased ROS production. In this model, NOX is activated, NOS activity is impaired, and ROS production is increased. Furthermore, treatment of animals with apocynin (a selective NOX inhibitor) normalizes NOX and NOS activities and restores the erectile function. Recent clinical and experimental data suggest that xanthine oxidase-dependent ROS production also induces endothelial dysfunction in muscular skeletal arteries $[29,30]$ and that xanthine oxidase inhibition by allopurinol reverses this phenomenon.

\section{Atherosclerosis}

Endothelial dysfunction is a precursor lesion for atherosclerosis. Consequently, OSA patients display increased common carotid artery-intima media thickness when compared with matched controls without sleep-disordered breathing [5]. Furthermore, CPAP therapy leads to a decrease of this noninvasive marker of atherosclerosis [31]. Animal studies support the concept that the enhanced atherosclerosis known to occur in OSA is due to increased vascular inflammation and lipid peroxidation in response to oxidative stress.

In this context, mice exposed to intermittent hypoxia exhibit increased leukocyte adhesion in their cortical venular microcirculation [32]. Another study reported increased flux of leukocytes rolling, a number of rolling leukocytes, and a number of adherent leukocytes in colonic venules following 3 hours of recurrent obstructive apneas in rats [33]. Of note, ROS may act as proinflammatory triggers by inducing NF- $\kappa \mathrm{B}$ and subsequently the expression of proinflammatory cytokines such as interleukin-6, tumor necrosis factor alpha and C-reactive protein [34].

In addition, they may exert proatherogenic effects by increasing lipid peroxidation as shown in a mouse model of OSA [35]. In accordance with these assumptions, direct 
evidence has been obtained in mice that $\mathrm{CIH}$ leads to the formation of atherosclerotic lesions. Exposure to CIH for 12 weeks induced the development of atherosclerotic plaques, but a concomitant high-cholesterol diet was necessary for that effect to occur [36].

\section{Arterial Hypertension}

Arterial hypertension is the most frequent $\mathrm{CV}$ complication of OSA and there is a significant dose-response relationship between the AHI and the odds ratio for developing arterial hypertension [37]. Animal studies have shown that various vasoactive mediator systems may be responsible for the pressor effect of $\mathrm{CIH}$ and that this is primarily mediated through an augmentation of carotid chemoreflex function.

In a series of experiments, Flechter et al. were among the first to show the importance of the sympathetic nervous system in this context. They demonstrated that surgical denervation of peripheral chemoreceptors prevented the increase in arterial blood pressure in response to $\mathrm{CIH}$. Adrenal demedullation and chemical denervation of the peripheral sympathetic nervous system by 6-hydroxy dopamine also prevented the increase in blood pressure [38,39].

Carotid chemoreflex sensitization caused by $\mathrm{CIH}$ may also be due to angiotensin-II-induced activation of NOX with subsequent production of ROS. Chronic exposure of rats to $\mathrm{CIH}$ results in elevation of plasma renin activity, and pharmacological inhibition of the renin-angiotensin-aldosterone system attenuates CIH-induced arterial hypertension [40]. Similar effects can be observed after ascorbic acid (an antioxidant vitamin [41]), tempol [42], and apocynin [43].

Finally, data from our laboratory show that NOX knockout blocks the development of arterial hypertension in response to $\mathrm{CIH}[44]$. As a more direct evidence, gene transcription of NOX subunits has been found to be upregulated in the carotid body in response to $\mathrm{CIH}$ [45].

The current concept is that $\mathrm{CIH}$ activates HIF-1 $\alpha$ thereby enhancing NOX2 transcription and ROS production [46]. On the other hand, it decreases HIF- $2 \alpha$-dependent SOD activation and thus leads to a reduced clearance of ROS [47]. Importantly, the ROS formed within the carotid body may exert their pressor effects by enhancing central sympathetic activity [48].

Endothelin-1 is another vasoactive mediator which is strongly upregulated in the carotid body in response to $\mathrm{CIH}$ and receptor antagonism by bosentan abolished abnormal chemosensitization $[49,50]$. In accordance with these findings, other groups have found that systemic administration of endothelin receptor antagonists to rats/mice prevents the increase of blood pressure during $\mathrm{CIH}[51,52]$.

In contrast to angiotensin and endothelin-1, NO inhibits carotid body chemosensitivity [53]. Rats exposed to $\mathrm{CIH}$ express less neuronal NO synthase [54], and stimulation of $\mathrm{NO}$ production by L-arginine restores the carotid body chemosensitivity [53] thus suggesting that an impaired bioavailability of NO might be responsible for enhanced carotid chemoreflex sensitivity under $\mathrm{CIH}$.

It should be mentioned that the OSA-associated arterial hypertension probably results not only from increased carotid chemoreflex but also from decreased baroreceptor activity. Finally, locally acting processes in peripheral blood vessels as discussed in Section 2 (i.e., reduced NO bioavailability) may play significant roles.

\section{Pulmonary Hypertension}

$20-30 \%$ of untreated OSA patients suffer from pulmonary arterial hypertension. It was first thought that this phenomenon is restricted to patients with pulmonary comorbidities such as COPD, but it is now widely accepted that OSA itself can lead to pulmonary hypertension [55]. Up to date, this aspect of OSA-associated CV morbidity has been less extensively investigated in animal models. A histomorphometric study showed that mice exposed to $\mathrm{CIH}$ develop characteristic features of pulmonary hypertension such as elevated pulmonary artery pressure, right ventricular hypertrophy, and muscularization of small pulmonary arteries [56]. Quite similar observations were later reported by another group [13]. Furthermore, it was demonstrated that NOX knockout mice are protected against the development of $\mathrm{CIH}$-associated pulmonary hypertension [57]. A more recent study showed that pulmonary vasodilatory capacity is impaired under conditions of $\mathrm{CIH}$ and that this is related to increased vascular superoxide anion production [58]. Thus, the same pathogenetic mechanisms which have been proposed for acute hypoxic pulmonary vasoconstriction [59] may be operative in OSA-associated pulmonary hypertension.

\section{Heart Failure}

OSA patients are also at increased risk for the development of chronic heart failure. This may be due to OSA-related arterial hypertension, coronary artery disease, and the direct negative inotropic effects of breathing against an occluded upper airway [60]. Experimental models of OSA support the notion that $\mathrm{CIH}$ negatively affects left ventricular (LV) function and that oxidative stress is an important mediator of myocardial damage.

Exposure of dogs to CIH induces LV hypertrophy and a decrease in ejection fraction [61]. Experimental CIH in rats/mice results in myocardial remodeling with myocyte hypertrophy and interstitial fibrosis finally leading to $\mathrm{LV}$ dysfunction [62,63]. Moreover, these studies suggest that an increased myocardial oxidative stress plays a significant role in this context. Chen et al. observed a significant inverse relationship between LV function and the myocardial content of lipid peroxides [62]. Furthermore, myocardial NOX subunit expression is increased in response to $\mathrm{CIH}[64,65]$, and NOX knock-out mice are obviously protected against the development of LV dysfunction in response to $\mathrm{CIH}$ [63]. Finally, treatment of mice with allopurinol significantly attenuates myocardial changes induced by $\mathrm{CIH}$ [66]. The exact mechanisms by which ROS induce LV dysfunction are not known, but it is largely accepted that oxidative stress causes a cytotoxic tissue injury by increased lipid peroxidation, protein oxidation, and direct DNA damage leading in 


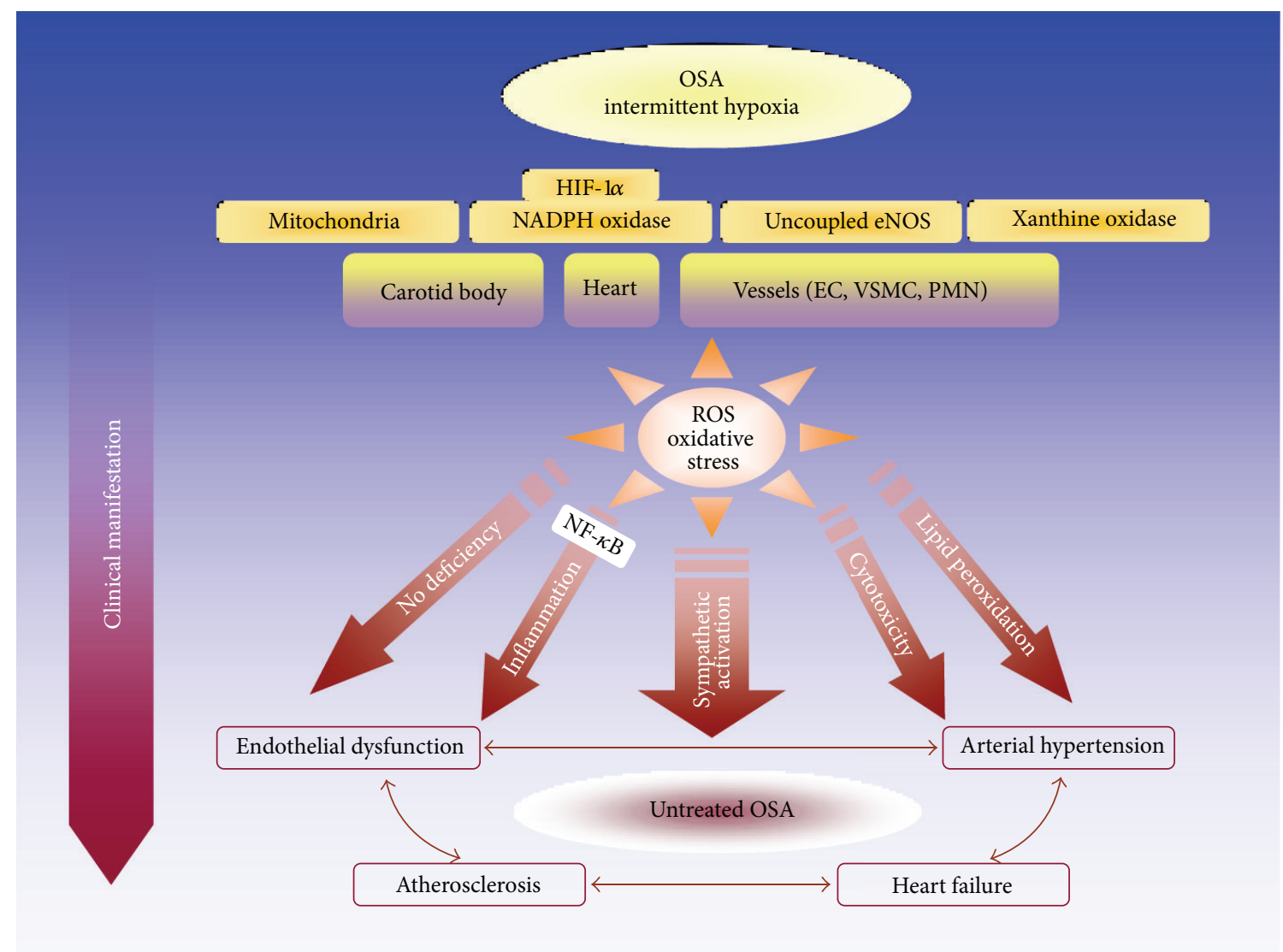

FIGURE 2: Simplified model of oxidative stress as the central pathogenetic pathway in OSA-associated CV diseases as suggested by animal studies. OSA-associated intermittent hypoxia activates NOX and other ROS-producing enzymes in the carotid body, the heart, and the vessels (PMN: polymorphonuclear neutrophils, EC: endothelial cells, VSMC: vascular smooth muscle cells). The resulting radical flux exerts direct cytotoxic effects, decreases NO bioavailability, enhances lipid peroxidation, increases sympathetic activity, and activates the proinflammatory transcription factor NF- $\kappa$ B. Finally, these changes lead to the well-known clinical manifestations of OSA in the CV system.

this way to apoptosis, necrosis, and abnormal tissue repair processes.

\section{Conclusions}

In this paper, we have briefly summarized the current state of knowledge about the pathophysiology of OSA-related CV diseases as provided by basic research conducted in animal models of OSA. Almost the complete clinical spectrum of $\mathrm{CV}$ diseases known to occur in humans with OSA has been replicated in animals subjected to $\mathrm{CIH}$. The common result of these studies is that an increased oxidative stress, mostly derived from an activation of NOX, seems to play a key role in the development of OSA-associated CV diseases (Figure 2).

It is anticipated that animal studies will continue to enhance our understanding of the pathogenesis of OSArelated $\mathrm{CV}$ diseases for instance by investigating knock-out and genetically engineered mice or by performing selective pharmacological interventions. In this way, the fundamental molecular pathways linking OSA to CV diseases may be identified and new cardioprotective treatment options may emerge for the relatively large proportion of OSA patients unable to tolerate CPAP therapy.

\author{
Abbreviations \\ AHI: Apnea-hypopneaindex \\ $\mathrm{CIH}$ : Chronic intermittent hypoxia \\ CPAP: Continuous positive airway pressure \\ CV: Cardiovascular \\ LV: Left ventricular \\ NO: Nitric oxide \\ NOS: Nitric oxide synthase \\ NOX: NADPH oxidase \\ OSA: Obstructive sleep apnea \\ ROS: Reactive oxygen species \\ SOD: Superoxide dismutase.
}

\section{Conflict of Interests}

The authors declare that they have no conflict of interests.

\section{References}

[1] D. J. Eckert and A. Malhotra, "Pathophysiology of adult obstructive sleep apnea," Proceedings of the American Thoracic Society, vol. 5, no. 2, pp. 144-153, 2008. 
[2] J. M. Marin, S. J. Carrizo, E. Vicente, and A. G. N. Agusti, "Longterm cardiovascular outcomes in men with obstructive sleep apnoea-hypopnoea with or without treatment with continuous positive airway pressure: an observational study," The Lancet, vol. 365, no. 9464, pp. 1046-1053, 2005.

[3] E. Shahar, C. W. Whitney, S. Redline et al., "Sleep-disordered breathing and cardiovascular disease: cross-sectional results of the sleep heart health study," American Journal of Respiratory and Critical Care Medicine, vol. 163, no. 1, pp. 19-25, 2001.

[4] T. Young, L. Finn, P. E. Peppard et al., "Sleep disordered breathing and mortality: eighteen-year follow-up of the wisconsin sleep cohort," Sleep, vol. 31, no. 8, pp. 1071-1078, 2008.

[5] R. Schulz, W. Seeger, C. Fegbeutel et al., "Changes in extracranial arteries in obstructive sleep apnoea," European Respiratory Journal, vol. 25, no. 1, pp. 69-74, 2005.

[6] J. T. Carlson, C. Rångemark, and J. A. Hedner, "Attenuated endothelium-dependent vascular relaxation in patients with sleep apnoea," Journal of Hypertension, vol. 14, no. 5, pp. 577584, 1996.

[7] L. Dyugovskaya, P. Lavie, and L. Lavie, "Increased adhesion molecules expression and production of reactive oxygen species in leukocytes of sleep apnea patients," American Journal of Respiratory and Critical Care Medicine, vol. 165, no. 7, pp. 934939, 2002.

[8] S. Ryan, C. T. Taylor, and W. T. McNicholas, "Selective activation of inflammatory pathways by intermittent hypoxia in obstructive sleep apnea syndrome," Circulation, vol. 112, no. 17, pp. 2660-2667, 2005.

[9] R. Schulz, S. Mahmoudi, K. Hattar et al., "Enhanced release of superoxide from polymorphonuclear neutrophils in obstructive sleep apnea: impact of continuous positive airway pressure therapy," American Journal of Respiratory and Critical Care Medicine, vol. 162, no. 2, part 1, pp. 566-570, 2000.

[10] V. K. Somers, M. E. Dyken, M. P. Clary, and F. M. Abboud, "Sympathetic neural mechanisms in obstructive sleep apnea," The Journal of Clinical Investigation, vol. 96, no. 4, pp. 1897-1904, 1995.

[11] Y. Tagaito, V. Y. Polotsky, M. J. Campen et al., "A model of sleep-disordered breathing in the C57BL/6J mouse," Journal of Applied Physiology, vol. 91, no. 6, pp. 2758-2766, 2001.

[12] V. A. Braga, R. N. Soriano, and B. H. Machado, "Sympathoexcitatory response to peripheral chemoreflex activation is enhanced in juvenile rats exposed to chronic intermittent hypoxia," Experimental Physiology, vol. 91, no. 6, pp. 1025-1031, 2006.

[13] M. J. Campen, L. A. Shimoda, and C. P. O’Donnell, "Acute and chronic cardiovascular effects of intermittent hypoxia in C57BL/6J mice," Journal of Applied Physiology, vol. 99, no. 5, pp. 2028-2035, 2005.

[14] M. Dematteis, C. Julien, C. Guillermet et al., "Intermittent hypoxia induces early functional cardiovascular remodeling in mice," American Journal of Respiratory and Critical Care Medicine, vol. 177, no. 2, pp. 227-235, 2008.

[15] E. C. Fletcher, J. Lesske, J. Culman, C. C. Miller, and T. Unger, "Sympathetic denervation blocks blood pressure elevation in episodic hypoxia," Hypertension, vol. 20, no. 5, pp. 612-619, 1992.

[16] E. C. Fletcher, J. Lesske, W. Qian et al., "Repetitive, episodic hypoxia causes diurnal elevation of blood pressure in rats," Hypertension, vol. 19, no. 6, part 1, pp. 555-561, 1992.

[17] D. Gozal, J. M. Daniel, and G. P. Dohanich, "Behavioral and anatomical correlates of chronic episodic hypoxia during sleep in the rat," Journal of Neuroscience, vol. 21, no. 7, pp. 2442-2450, 2001.

[18] C. Julien, B. Sam, and L. Patrick, "Vascular reactivity to norepinephrine and acetylcholine after chronic intermittent hypoxia in mice," Respiratory Physiology and Neurobiology, vol. 139, no. 1, pp. 21-32, 2003.

[19] J. B. Klein, M. T. Barati, R. Wu et al., "Akt-mediated valosincontaining protein 97 phosphorylation regulates its association with ubiquitinated proteins," The Journal of Biological Chemistry, vol. 280, no. 36, pp. 31870-31881, 2005.

[20] V. Y. Polotsky, A. E. Rubin, A. Balbir et al., "Intermittent hypoxia causes REM sleep deficits and decreases EEG delta power in NREM sleep in the C57BL/6J mouse," Sleep Medicine, vol. 7, no. 1, pp. 7-16, 2006.

[21] D. B. Zoccal, A. E. Simms, L. G. H. Bonagamba et al., "Increased sympathetic outflow in juvenile rats submitted to chronic intermittent hypoxia correlates with enhanced expiratory activity," Journal of Physiology, vol. 586, no. 13, pp. 3253-3265, 2008.

[22] R. Farré, M. Nácher, A. Serrano-Mollar et al., "Rat model of chronic recurrent airway obstructions to study the sleep apnea syndrome," Sleep, vol. 30, no. 7, pp. 930-933, 2007.

[23] R. J. Kimoff, H. Makino, R. L. Horner et al., "Canine model of obstructive sleep apnea: model description and preliminary application," Journal of Applied Physiology, vol. 76, no. 4, pp. 1810-1817, 1994.

[24] M. S. M. Ip, H. F. Tse, B. Lam, K. W. T. Tsang, and W. K. Lam, "Endothelial function in obstructive sleep apnea and response to treatment," American Journal of Respiratory and Critical Care Medicine, vol. 169, no. 3, pp. 348-353, 2004.

[25] Z. Tahawi, N. Orolinova, I. G. Joshua, M. Bader, and E. C. Fletcher, "Altered vascular reactivity in arterioles of chronic intermittent hypoxic rats," Journal of Applied Physiology, vol. 90, no. 5, pp. 2007-2013, 2001.

[26] S. A. Phillips, E. B. Olson, J. H. Lombard, and B. J. Morgan, "Chronic intermittent hypoxia alters NE reactivity and mechanics of skeletal muscle resistance arteries," Journal of Applied Physiology, vol. 100, no. 4, pp. 1117-1123, 2006.

[27] H. Xie, P. E. Ray, and B. L. Short, "NF- $\kappa$ B activation plays a role in superoxide-mediated cerebral endothelial dysfunction after hypoxia/reoxygenation," Stroke, vol. 36, no. 5, pp. 1047-1052, 2005.

[28] K. Liu, X. S. Liu, L. Xiao et al., "NADPH oxidase activation: a mechanism of erectile dysfunction in a rat model of sleep apnea," Journal of Andrology, vol. 33, no. 6, pp. 1186-1198, 2012.

[29] J. M. Dopp, N. R. Philippi, N. J. Marcus et al., "Xanthine oxidase inhibition attenuates endothelial dysfunction caused by chronic intermittent hypoxia in rats," Respiration, vol. 82, no. 5, pp. 458467, 2011.

[30] A. A. El Solh, R. Saliba, T. Bosinski, B. J. B. Grant, E. Berbary, and N. Miller, "Allopurinol improves endothelial function in sleep apnoea: a randomised controlled study," European Respiratory Journal, vol. 27, no. 5, pp. 997-1002, 2006.

[31] L. F. Drager, L. A. Bortolotto, M. C. Lorenzi, A. C. Figueiredo, E. M. Krieger, and G. Lorenzi-Filho, "Early signs of atherosclerosis in obstructive sleep apnea," American Journal of Respiratory and Critical Care Medicine, vol. 172, no. 5, pp. 613-618, 2005.

[32] T. Altay, E. R. Gonzales, T. S. Park, and J. M. Gidday, "Cerebrovascular inflammation after brief episodic hypoxia: modulation by neuronal and endothelial nitric oxide synthase," Journal of Applied Physiology, vol. 96, no. 3, pp. 1223-1230, 2004. 
[33] M. Nácher, A. Serrano-Mollar, R. Farré, J. Panés, J. Seguí, and J. M. Montserrat, "Recurrent obstructive apneas trigger early systemic inflammation in a rat model of sleep apnea," Respiratory Physiology and Neurobiology, vol. 155, no. 1, pp. 9396, 2007.

[34] H. Greenberg, X. Ye, D. Wilson, A. K. Htoo, T. Hendersen, and S. F. Liu, "Chronic intermittent hypoxia activates nuclear factor- $\kappa \mathrm{B}$ in cardiovascular tissues in vivo," Biochemical and Biophysical Research Communications, vol. 343, no. 2, pp. 591596, 2006.

[35] J. Li, V. Savransky, A. Nanayakkara, P. L. Smith, C. P. O’Donnell, and V. Y. Polotsky, "Hyperlipidemia and lipid peroxidation are dependent on the severity of chronic intermittent hypoxia," Journal of Applied Physiology, vol. 102, no. 2, pp. 557-563, 2007.

[36] V. Savransky, A. Nanayakkara, J. Li et al., "Chronic intermittent hypoxia induces atherosclerosis," American Journal of Respiratory and Critical Care Medicine, vol. 175, no. 12, pp. 1290-1297, 2007.

[37] P. E. Peppard, T. Young, M. Palta, and J. Skatrud, "Prospective study of the association between sleep-disordered breathing and hypertension," The New England Journal of Medicine, vol. 342, no. 19, pp. 1378-1384, 2000.

[38] G. Bao, P. M. Randhawa, and E. C. Fletcher, "Acute blood pressure elevation during repetitive hypocapnic and eucapnic hypoxia in rats," Journal of Applied Physiology, vol. 82, no. 4, pp. 1071-1078, 1997.

[39] E. C. Fletcher, J. Lesske, J. Culman, C. C. Miller, and T. Unger, "Sympathetic denervation blocks blood pressure elevation in episodic hypoxia," Hypertension, vol. 20, no. 5, pp. 612-619, 1992.

[40] E. C. Fletcher, N. Orolinova, and M. Bader, "Blood pressure response to chronic episodic hypoxia: the renin-angiotensin system," Journal of Applied Physiology, vol. 92, no. 2, pp. 627633, 2002.

[41] R. Del Rio, E. A. Moya, and R. Iturriaga, "Carotid body and cardiorespiratory alterations in intermittent hypoxia: the oxidative link," European Respiratory Journal, vol. 36, no. 1, pp. 143-150, 2010.

[42] C. M. Troncoso Brindeiro, A. Q. da Silva, K. J. Allahdadi, V. Youngblood, and N. L. Kanagy, "Reactive oxygen species contribute to sleep apnea-induced hypertension in rats," American Journal of Physiology, vol. 293, no. 5, pp. H2971-H2976, 2007.

[43] G. K. Kumar, V. Rai, S. D. Sharma et al., "Chronic intermittent hypoxia induces hypoxia-evoked catecholamine efflux in adult rat adrenal medulla via oxidative stress," The Journal of Physiology, vol. 575, part 1, pp. 229-239, 2006.

[44] G. Murzabekova, H.-J. Eisele, B. Egemnazarov et al., "Arterial hypertension in a murine model of sleep apnea-role of NADPH oxidases," American Journal of Respiratory and Critical Care Medicine, vol. 181, p. A2480, 2010.

[45] S. Y. Lam, Y. Liu, K. M. Ng et al., "Chronic intermittent hypoxia induces local inflammation of the rat carotid body via functional upregulation of proinflammatory cytokine pathways," Histochemistry and Cell Biology, vol. 137, no. 3, pp. 303-317, 2012.

[46] G. Yuan, S. A. Khan, W. Luo, J. Nanduri, G. L. Semenza, and N. R. Prabhakar, "Hypoxia-inducible factor 1 mediates increased expression of NADPH oxidase-2 in response to intermittent hypoxia," Journal of Cellular Physiology, vol. 226, no. 11, pp. 2925-2933, 2011.

[47] G. L. Semenza, "Hypoxia-inducible factors in physiology and medicine," Cell, vol. 148, no. 3, pp. 399-408, 2012.
[48] N. R. Prabhakar, G. K. Kumar, and Y. J. Peng, "Sympathoadrenal activation by chronic intermittent hypoxia," Journal of Applied Physiology, vol. 113, no. 8, pp. 1304-1310, 2012.

[49] J. Chen, L. He, B. Dinger, and S. Fidone, "Cellular mechanisms involved in rabbit carotid body excitation elicited by endothelin peptides," Respiration Physiology, vol. 121, no. 1, pp. 13-23, 2000.

[50] S. Rey, R. Del Rio, and R. Iturriaga, "Contribution of endothelin1 to the enhanced carotid body chemosensory responses induced by chronic intermittent hypoxia," Brain Research, vol. 1086, no. 1, pp. 152-159, 2006.

[51] E. Belaidi, M. Joyeux-Faure, C. Ribuot, S. H. Launois, P. Levy, and D. Godin-Ribuot, "Major role for hypoxia inducible factor1 and the endothelin system in promoting myocardial infarction and hypertension in an animal model of obstructive sleep apnea," Journal of the American College of Cardiology, vol. 53, no. 15, pp. 1309-1317, 2009.

[52] N. L. Kanagy, B. R. Walker, and L. D. Nelin, "Role of endothelin in intermittent hypoxia-induced hypertension," Hypertension, vol. 37, no. 2, part 2, pp. 511-515, 2001.

[53] S. Y. Sun, W. Wang, I. H. Zucker, and H. D. Schultz, "Enhanced activity of carotid body chemoreceptors in rabbits with heart failure: role of nitric oxide," Journal of Applied Physiology, vol. 86, no. 4, pp. 1273-1282, 1999.

[54] N. J. Marcus, Y. L. Li, C. E. Bird, H. D. Schultz, and B. J. Morgan, "Chronic intermittent hypoxia augments chemoreflex control of sympathetic activity: role of the angiotensin II type 1 receptor," Respiratory Physiology and Neurobiology, vol. 171, no. 1, pp. 3645, 2010.

[55] D. Sajkov and R. D. McEvoy, "Obstructive sleep apnea and pulmonary hypertension," Progress in Cardiovascular Diseases, vol. 51, no. 5, pp. 363-370, 2009.

[56] K. A. Fagan, "Selected contribution: pulmonary hypertension in mice following intermittent hypoxia," Journal of Applied Physiology, vol. 90, no. 6, pp. 2502-2507, 2001.

[57] R. E. Nisbet, A. S. Graves, D. J. Kleinhenz et al., "The role of NADPH oxidase in chronic intermittent hypoxia-induced pulmonary hypertension in mice," American Journal of Respiratory Cell and Molecular Biology, vol. 40, no. 5, pp. 601-609, 2009.

[58] C. E. Norton, N. L. Jernigan, N. L. Kanagy, B. R. Walker, and T. C. Resta, "Intermittent hypoxia augments pulmonary vascular smooth muscle reactivity to NO: regulation by reactive oxygen species," Journal of Applied Physiology, vol. 111, no. 4, pp. 980988, 2011.

[59] N. Sommer, A. Dietrich, R. T. Schermuly et al., "Regulation of hypoxic pulmonary vasoconstriction: basic mechanisms," European Respiratory Journal, vol. 32, no. 6, pp. 1639-1651, 2008.

[60] K. Kee and M. T. Naughton, "Heart failure and sleep-disordered breathing: mechanisms, consequences and treatment," Current Opinion in Pulmonary Medicine, vol. 15, no. 6, pp. 565-570, 2009.

[61] J. D. Parker, D. Brooks, L. F. Kozar et al., "Acute and chronic effects of airway obstruction on canine left ventricular performance," American Journal of Respiratory and Critical Care Medicine, vol. 160, no. 6, pp. 1888-1896, 1999.

[62] L. Chen, E. Einbinder, Q. Zhang, J. Hasday, C. W. Balke, and S. M. Scharf, "Oxidative stress and left ventricular function with chronic intermittent hypoxia in rats," American Journal of Respiratory and Critical Care Medicine, vol. 172, no. 7, pp. 915920, 2005.

[63] T. Hayashi, C. Yamashita, C. Matsumoto et al., "Role of gp9lphox-containing NADPH oxidase in left ventricular 
remodeling induced by intermittent hypoxic stress," American Journal of Physiology, vol. 294, no. 5, pp. H2197-H2203, 2008.

[64] A. Ramond, D. Godin-Ribuot, C. Ribuot et al., "Oxidative stress mediates cardiac infarction aggravation induced by intermittent hypoxia," Fundamental \& Clinical Pharmacology, 2011.

[65] W. Zhou, S. Li, N. Wan, Z. Zhang, R. Guo, and B. Chen, "Effects of various degrees of oxidative stress induced by intermittent hypoxia in rat myocardial tissues," Respirology, vol. 17, no. 5, pp. 821-829, 2012.

[66] A. L. Williams, L. Chen, and S. M. Scharf, "Effects of allopurinol on cardiac function and oxidant stress in chronic intermittent hypoxia," Sleep and Breathing, vol. 14, no. 1, pp. 51-57, 2010. 


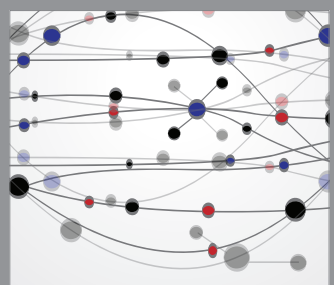

The Scientific World Journal
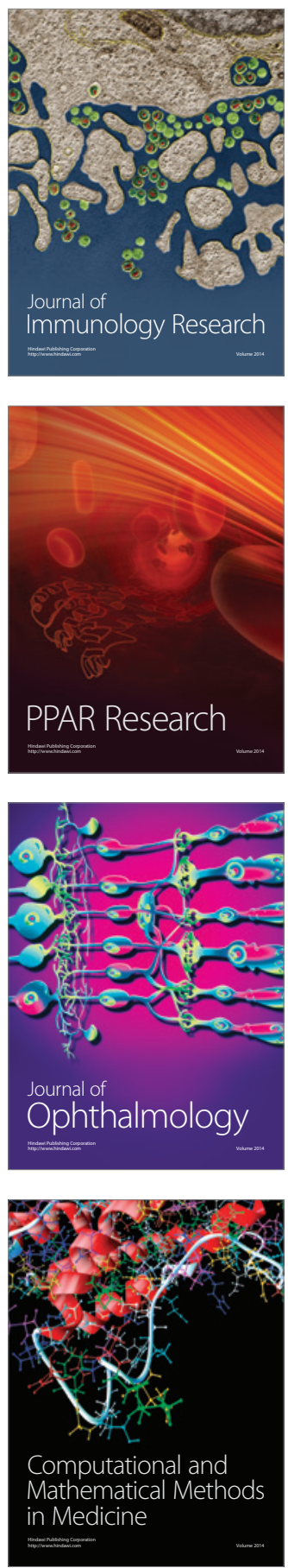

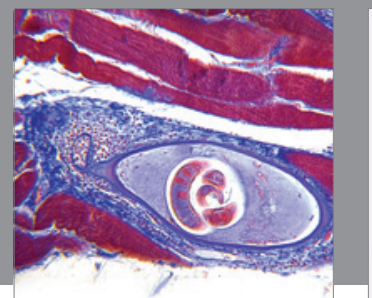

Gastroenterology

Research and Practice
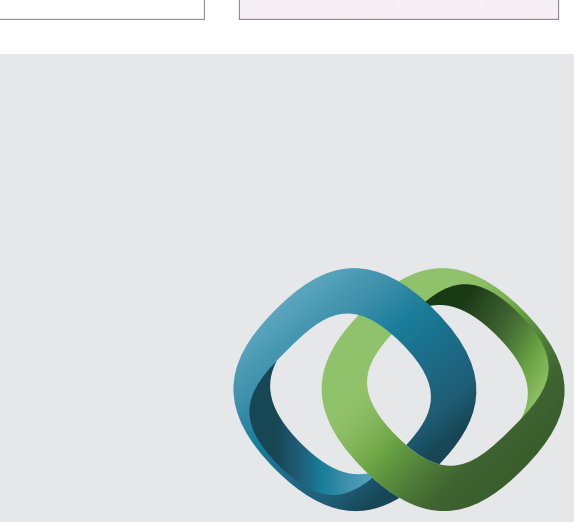

\section{Hindawi}

Submit your manuscripts at

http://www.hindawi.com
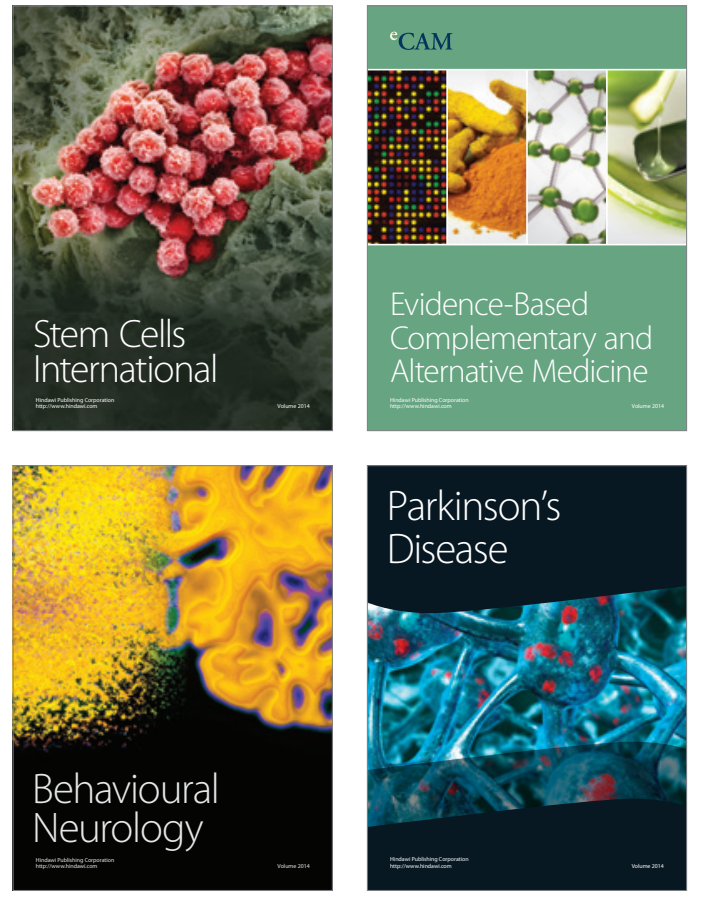
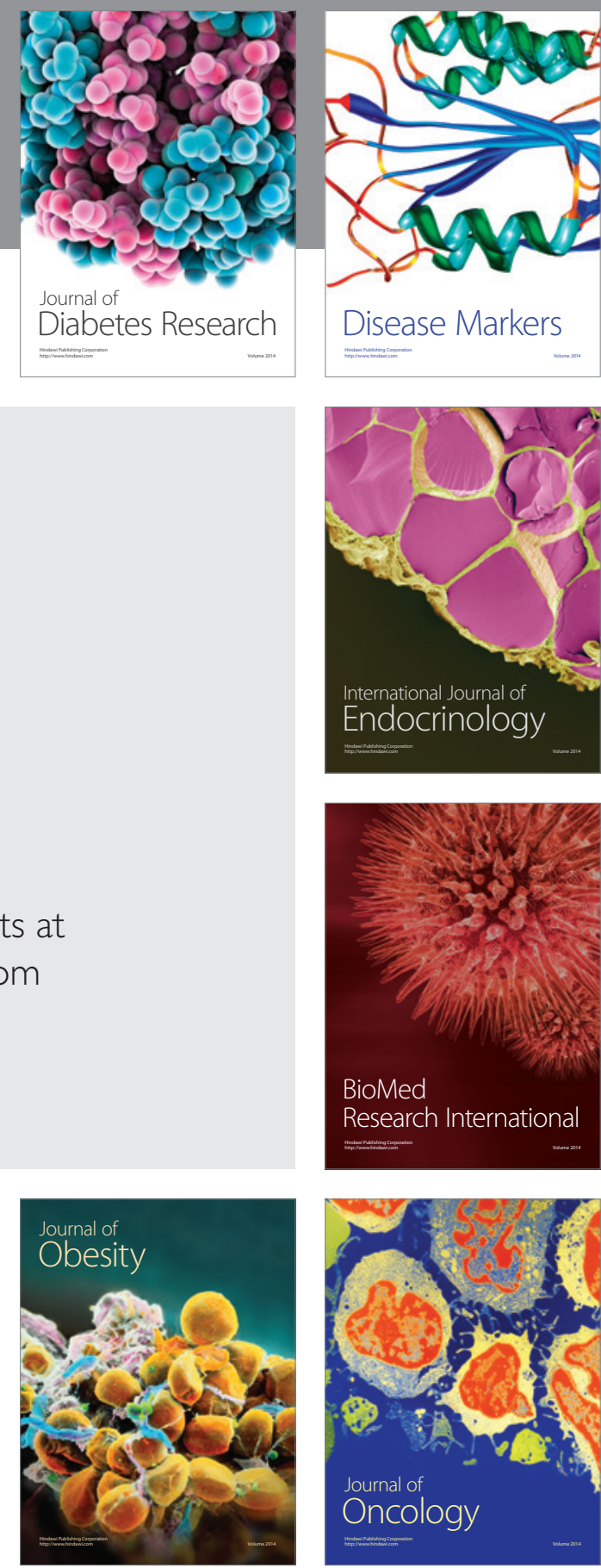

Disease Markers
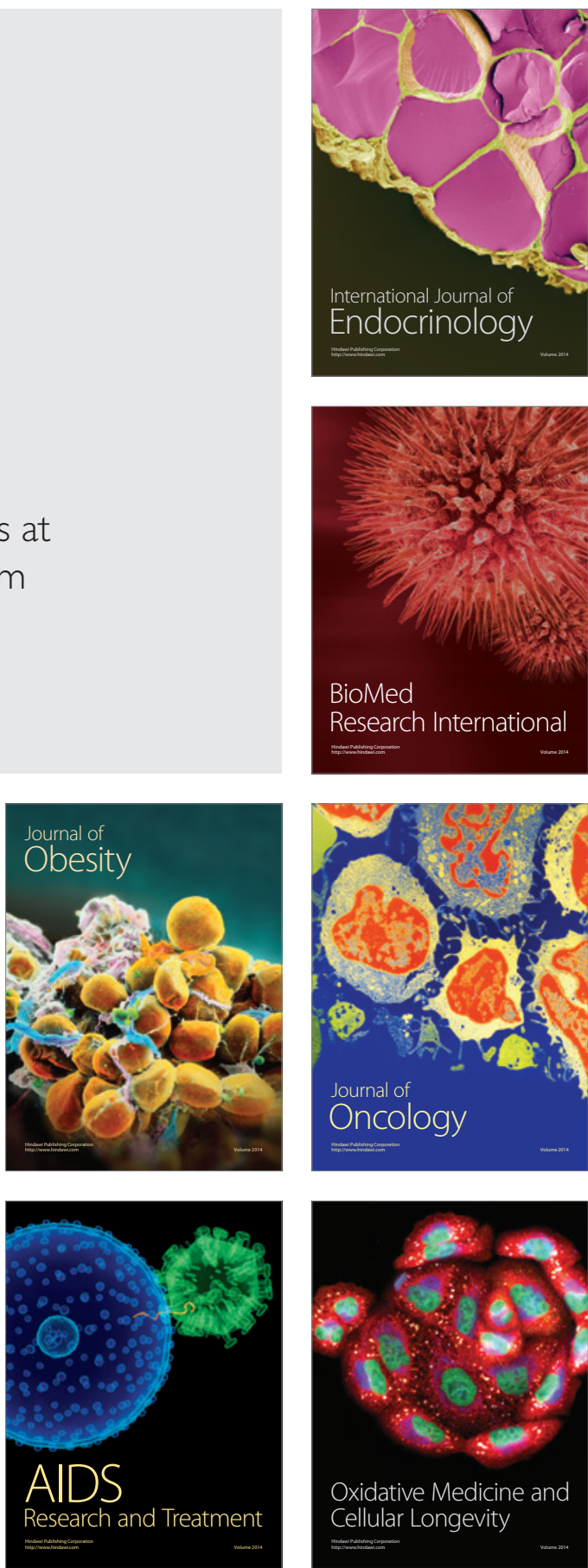